\title{
The circular economy and the water-food nexus
}

\author{
Robert C. Brears *1 \\ 1. Robert C. Brears is the founder of Mitidaption, Mark and Focus, and a Visiting Scholar at MIIS, Monterey, United States \\ Email:rcb.chc@gmail.com
}

\section{Data of the article}

First received: 28 July 2015 | Last revision received: 04 November 2015

Accepted: 07 November 2015 | Published online: 16 December 2015

URN :nbn:de:hebis:34-2015102649198

\section{Key words}

water; agriculture; phosphorus; circular economy

\begin{abstract}
The global economy is based on a take-make-consume and dispose model where natural resources are turned into products and the waste disposed of instead of being reused as a resource. In the Asia-Pacific region climate change along with rapid population and economic growth is resulting in increased demand for water and food, potentially leading to economic and political instability. Europe has developed policy and technological innovations that can facilitate the transition towards a circular economy where waste becomes a resource. By using existing instruments Europe can transfer its circular economy knowledge and technology to the Asia-Pacific region to increase security of supply of scarce resources. This can help ensure global security, influence climate change negotiations and create jobs in Europe.
\end{abstract}

\section{Introduction}

Since the industrial revolution the total amount of waste has constantly grown as economic growth has been based on a 'take-make-consume and dispose' model (European Commission, 2014). This linear model assumes that resources are abundant, available and cheap to dispose of. In Europe there is a move towards a 'circular economy' that reduces, reuses and recovers resources, which in turn reduces primary resource consumption and greenhouse gas emissions (EEA, 2014, WEF, 2014).

In the Asia-Pacific region rapid urbanization and economic growth has led to environmental degradation and resource scarcity: land for food production has become a fragile resource while three out of four countries currently face water scarcity (LSE Cities, 2014, ABD, 2013). Regarding water and food, accessibility and availability of water resources has historically influenced agricultural production in- cluding types of crops grown, crop cycles and irrigation methods adopted. However, this 'water-food nexus' has become vulnerable to changing patterns of water supply from climate change and growing competition for limited water resources, affecting the production of food resources. In addition, the use of fertilizers has increased significantly as demand for food has increased, impacting water quality for natural and human uses (IRENA, 2015). A move towards a circular economy is therefore critical for ensuring economic and social stability in a region that is vital to the world. As such, it is only through closer ties and co-ordination with partners in the Asia-Pacific region that the EU can address major global issues including climate change and resource scarcity. The EU would also gain through job creation and increased economic productivity from producing innovations to further develop the circular economy. 


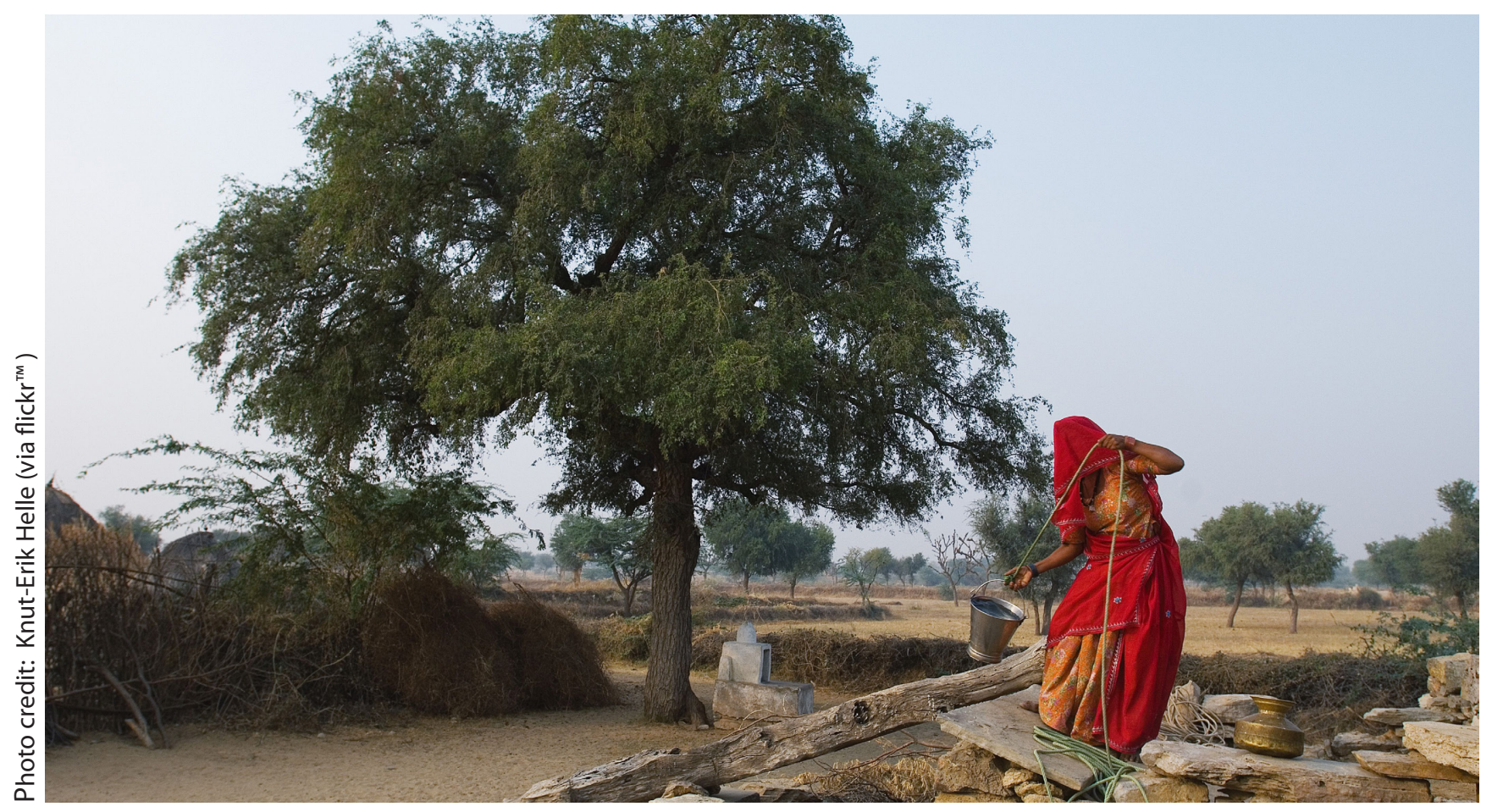

Figure 1: Access to improved water is a big challenge in many parts of the world

\section{Water-food nexus pressures in Asia-Pacific}

Water for food production accounts for around $70 \%$ of water withdrawals. However, with increases in population growth, urbanisation and economic growth along with changes in diet as prosperity increases, demand for food will increase significantly. For instance, a change in lifestyle and diets in Asia will increase demand for water-intensive products such as meat and dairy products (FAO, 2013). Globally, demand for phosphate as a fertilizer nutrient will rise from 43.8 million tonnes per annum in 2015 to 52.9 million tonnes in 2030 (European Commission, 2013). Currently, Asia accounts for almost $60 \%$ of the world's total nutrient use, with China and India consuming around $55 \%$ and $29 \%$ of Asia's total consumption of fertilizer respectively. Over the next five years, Asia's consumption of fertilizer will increase by around $6 \%$ due to changing and interconnected trends including economic and population growth and increased demand for food (PR News Wire, 2014).

Why should the EU help reduce nexus pressures? Addressing environmental degradation, climate change, resource efficiency and water management are key priorities for the EU in the Asia-Pacific region for the following reasons:

\section{Global security:}

Increased demand for water and food accompanied by the impact of climate change will affect the supply of natural resources. In many countries this will exacerbate exisiting difficulties including economic weakness, lack of adequate infrastructure and weak governance with potential competition over scarce resources, including water between states (Herman and Treverton, 2009). This will spur the search for new resources and the use of existing resources sustainably and efficiently through new technologies. These challenges provide unprecedented opportunities for the EU to offer its policy-making and technological expertise in ways that can underpin global security and prosperity in a sustainable manner.

\section{Job creation:}

At the aggregate EU-wide level, resource productivity in the EU grew by $20 \%$ between 2000 and 2011. While some of the increases in efficiency was due to the effects of the recession, if this rate was maintained it would lead to a further $30 \%$ increase in efficiency by 2030 and boost GDP by nearly $1 \%$, resulting in an additional 2 million jobs (European Commission, 2014). In addition, if European companies implement waste prevention, eco-design, 
reuse and other similar measures it could bring net savings of EUR 600 billion while reducing annual greenhouse gas emissions by 2-4\% (European Commission 2014). At the same time, the global market for eco-innovation, which is currently worth around EUR 1 trillion per annum is expected to triple by 2030 (European Commission 2015). As such, eco-innovation represents a major opportunity to boost competitiveness and create jobs in European economies (European Commission 2014).

\section{Influence in climate change negotiations:}

The EU has set itself the aim of negotiating and implementing a global climate change deal in 2015. To deliver on this, the EU will need to develop co-operation between key countries by encouraging them to commit to a sustainable low-carbon development path. This will include helping them manage their rapid urbanization in a low-carbon, climate resilient and sustainable manner. In addition, if greenhouse gas emissions are to be maintained at a low level that avoids catastrophic climate change, the EU will have to forge alliances with major emitters in areas including long-term business co-operation on low-carbon solutions.

\section{Europe's transition towards the circular economy}

In 2014 the European Commission adopted the Communication Paper 'Towards a circular economy: A zero waste programme for Europe' in order to establish a common and coherent EU framework for promoting the circular economy. Transitioning towards the circular economy involves: increasing recycling and preventing the loss of valuable materials, showing how new business models, eco-designs and industrial symbiosis can achieve zero-waste, reduce greenhouse gas emissions while also creating jobs and economic growth (European Commission, 2014). To achieve the circular economy the Communication paper proposes:

\section{Setting up an enabling policy framework:}

The European Commission proposes to establish a common and coherent EU framework to promote the circular economy. In particular, the Commission views markets as an important driving force in achieving a circular economy with materials and energy being the principal costs for many companies. However, there are many market barriers to the efficient management of resources. For example, waste prevention, eco-design, and reuse could save nearly $8 \%$ of annual turnover for European businesses, while reducing significantly greenhouse gas emissions (European Commission 2014). For this to happen, market barriers that prevent these opportunities from being developed need to be removed. Existing infrastructure, business models and technology all become 'locked-in' to the linear model of take-make-consume and dispose (European Commission, 2014). Companies may lack information, confidence, or capacity to implement circular economy solutions. The financial system is also a barrier. Circular economy companies can fail to raise capital for innovative solutions that increase efficiency or innovative business models that promote circular economy solutions, because they are perceived as being more risky, and so deter traditional investors. Finally, consumer habits may lockin linear models hindering the development of new circular economy products and services. This happens when prices do not reflect the real costs of resource use to society, and policy does not provide a strong enough signal for the transition towards a circular economy. Utilising evidence of successful products, materials and value chains, the European Commission plans to work with stakeholders to develop an enabling framework that uses smart regulations, market-based instruments, research and innovations, incentives, information exchange and support for voluntary approaches. To implement the circular economy and achieve a 'sustainable industrial renaissance' in Europe, the EU will rely on proactive businesses and consumers with a special focus on small and medium-sized enterprises (SMEs) implementing circular economy solutions.

\section{Designing and innovating for a circular economy:}

In circular economy innovations, the goal is to design out waste throughout the value chain, rather than relying on solutions at the end of a product's life. This can be achieved through activities that include: reducing the quantity of materials required to deliver a particular service (also known as lightweighting); reducing the use of energy in production and use phases (efficiency); reducing the use of materials that are hazardous or difficult to recycle in products and production processes (substitution); creating a market for secondary raw materials (also known as recyclates); designing products 
that are easier to recycle (eco-design); developing the necessary services for consumers (infrastructure); incentivizing and supporting waste reduction and high-quality separation by consumers (incentives); and facilitating the clustering of activities to prevent by-products from becoming waste (industrial symbiosis) (European Commission 2014).

Unlocking investment in circular economy solutions and harnessing the action of businesses by supporting SMEs:

As businesses are the key actors in a transition towards the circular economy, upstream and downstream decisions need to be better connected, with clear incentives between producers, investors, distributors, consumers and recyclers. In addition to using market mechanisms to ensure the efficient allocation of resources, a functioning secondary materials market needs to be developed. More attention also needs to be paid to enabling entrepreneurs to tap into potential new markets linked to the circular economy. The Commission's Communication Paper itself recommends the EU should encourage investment in circular economy innovations and address barriers to mobilizing more private financing for resource efficiency.

Modernizing waste policy and targets by turning waste into a resource:

Turning waste into a resource is part of 'closing the loop' in the circular economy. Objectives and targets set in European legislation are crucial drivers in improved waste management as they stimulate innovation in recycling and reuse, limit landfilling, reduce losses of resources, and create incentives for behavioural change. The EU has a political commitment to reduce waste generation, to recycle waste into a major, reliable source of raw materials, to recover energy only from non-recyclable materials and eliminate landfilling. For example, garden waste can be treated at composting plants, allowing the nutrients to be recycled as fertilizer (The Danish Government, 2013). The benefit of reducing waste is growth and job creation at relatively no cost, while also enhancing the environment. To boost the economic, social and environmental benefits gained from better management of municipal waste, the Commission proposes to increase reuse and recycling of municipal waste to a minimum of $70 \%$ by 2030 , ban the landfilling of recyclable waste and biodegradable waste by 2025 , and promote the development of markets for high quality secondary raw materials.

\section{Europe, the circular economy and water-food nexus pressures'}

Towards a circular economy: A zero waste programme for Europe' and the 2011 'Roadmap to a Resource Efficient Europe' identified the sustainable supply of phosphorous as an important factor affecting sustainability and long-term global food security. The mineral is an essential building block of life and is an irreplaceable part of modern agricultural production in its use as an animal feed and fertilizer. Despite phosphorous resources being abundant globally, there are three issues affecting the availability of supply, both in the EU and globally. First, there are only small reserves of phosphate-bearing rocks in the EU, with only Finland being a small producer. It is estimated that $90 \%$ of the world's phosphorous reserves are located in just five countries: China, Morocco, South Africa, Jordan and the United States. This has led to the EU importing $92 \%$ of its phosphorous. Second, there has been price volatility - in 2008 prices of phosphorous rose by $700 \%$ in just over a year resulting in increased fertilizer and food prices. Third, there is little possibility of reducing non-essential use of phosphorous as its use in animal feed and fertilizer already consumes around $90 \%$ of the total mined resource (European Commission 2013). Improving the use of recycled phosphorous in the EU and globally would therefore help safeguard the supply of this critical raw material.

\section{Reducing water-food nexus pressures in the UK}

In the United Kingdom (UK), the House of Common's Environmental Audit Committee's 2014 report, 'Growing a circular economy: Ending a throwaway society' stated that in 2012-13 household recycling rates had reached $43 \%$ in England, up from $12 \%$ in 2000-01. It is estimated that in 2010 the UK economy was $22 \%$ 'circular', up from $8 \%$ in 2000. Developments in circular economy technologies could mean that by 2030 the UK economy's circularity increases to $27 \%$, leading to a reduction in material consumption of $\mathbf{3 0}$ million tonnes a year (House of Commons 2014). Waste policy and regu- 
lation in England is informed by a 'Waste Hierarchy' where the top priority is waste prevention. This is followed by preparing for re-use, recycling, other types of recovery (including energy recovery) and last of all disposal or landfill. The economic benefits of achieving a circular economy to the UK's GDP could be an increase of GBP 3 billion a year, while businesses could save GBP 23 billion from low/no cost improvements (House of Commons 2014). By implementing EU circular economy and waste reduction initiatives, the UK could save GBP 9 billion a year while adding 50,000 more jobs. In the manufacturing sector, re-manufacturing has the potential to create between GBP 5.6-8 billion per annum and support over 310,000 jobs (House of Commons 2014).

An example from the UK of reducing water-food nexus pressures in the circular economy can be seen in an initiative by Thames Water, the largest water and sewage company in the UK. Thames Water has partnered with Ostra Nutrient Recovery Technologies to launch the UK's first nutrient recover facility at Slough Sewage Treatment Works producing commercial fertilizer from wastewater. Phosphorous and nitrogen concentrated in the facility's wastewater can form a concrete-like substance called struvite which coats pipes and valves, reducing the plants efficiency in treating wastewater - an energy-intensive process resulting in costly maintenance. The plant's nutrient recovery system addresses these issues by converting the struvite into pellets of high-grade fertilizer. The plant is expected to produce 150 tonnes of fertilizer pellets a year for sale to crop-growers as well as gardeners. Economically, the plant will also save GBP 200,000 per annum by avoiding operation and maintenance costs. The important lessons from this example that can be exported to the Asia-Pacific region are that circular economy technologies can: increase efficiency in operations and reduce maintenance costs; increase security of supply of scarce resources, in this case fertilizer for food production; and finally, reduce energy requirements and water use. However, to close the loop it is important to create a viable market for secondary raw material, thus turning waste into a resource.

Tools to transfer circular economy instruments The EU can use market access tools and innovation funding to expedite the transfer of circular economy knowledge and innovations from Europe to Asia-Pacific. These can help reduce tensions over scarce resources, reduce carbon emissions and support economic growth in Europe.

\section{Market access tools for Green SMEs:}

The EU's 'Green Action Plan for Small and Medium-sized Enterprises' provides a framework for how the EU and Member States should enable SMEs to turn environmental challenges into corporate opportunities as part of the transition towards a circular economy. One aspect of the Green Action Plan is to facilitate market access for Green SMEs. Over the period 2008-2014, the EU provided the'EU Gateway', which was a EU-funded initiative for helping SMEs establish long-lasting business collaborations in difficult markets abroad. In Asia, the programme targeted Japan and Korea. As part of this programme, EU Gateway provided SME participants a one-week in-country business mission along with business support services such as coaching, logistical and financial support. Over the period 2008-2014, 46 business missions were organised to visit Japan and Korea. Of the 1,500 participating companies: $83 \%$ found the business mission highly useful to increasing their market understanding; $64 \%$ established business collaborations; and 30\% saw their revenue grow following the mission (EU Gateway 2014). Building on the success of this programme, the EU has developed the 'EU Business Avenues to South East Asia' program which focuses on the Singapore, Malaysia and Vietnam markets. In 2015, the programme will be conducting business missions to these three countries for European SMEs in the clean technology sector. Particular focus will be given to SMEs focusing on water technology, the environment, renewable energy or energy efficiency, either as a producer of a sub-contractor or as an $R \& D$ or engineering company with its own technology. Horizon 2020 - funding circular economy innovation: Horizon 2020 is the largest EU's largest ever research and innovation programme, with almost EUR 80 billion of funding available from 2014 to 2020. The purpose of this funding is to take breakthroughs, discoveries and world-firsts from the lab to the market. Horizon 2020's funding will reflect the policy priorities of the Europe 2020 strategy and address major societal concerns shared by citizens of Europe and elsewhere. One of the main soci- 
etal challenges Horizon 2020 addresses is entitled 'Climate Action, Environment, Resource Efficiency and Raw Materials'. Activities in this challenge are intended to help increase European competitiveness, raw material security and improve wellbeing. At the same time the challenge will help assure environmental integrity, resilience and sustainability with the aim of keeping global warming below $2^{\circ} \mathrm{C}$ and enabling ecosystems and society to adapt to climate change and other environmental changes. The objectives of the challenge are to achieve a resource and water efficient as well as climate change resilient economy and society; protection and sustainable management of natural resources and ecosystems; and a sustainable supply and use of raw materials for meeting the needs of a rapidly growing global population within the sustainable limits of the planet's natural resources and eco-system. Research and innovation in this challenge will cover: adapting to climate change; protecting the environment and sustainably managing natural resources and ecosystems; ensuring the sustainable supply of raw materials; and enabling a transition towards a green economy through eco-innovation. Through Horizon 2020 funding, breakthroughs in circular economy technologies will be taken to the market, including in the Asia-Pacific region.

Horizon 2020 also calls for the strengthening of international co-operation with China and India, something to be achieved through strategic partnerships. These strategic partnerships will allow countries in the Asia-Pacific region to draw on Europe's experiences and lessons on how circular economy technology and eco-designs can reduce greenhouse gas emissions, increase resource efficiency and reduce water-food nexus pressures by turning waste into resources. Overall, by exporting Horizon 2020 lessons to the Asia-Pacific region the EU will enhance its economic competitiveness by increasing jobs through exports of circular technologies, while improving the security of non-energy raw materials, increasing human wellbeing, fighting climate change and limiting environmental degradation.

\section{Conclusion}

In the Asia-Pacific region, population growth, urbanization and economic growth along with changes in diet will increase demand for food significantly.
However, water resources in the region are vulnerable to changing patterns of supply and growing competition creating water-food nexus pressures. At the same time, demand for scarce phosphorous supplies will increase. With resource scarcity there is the potential for economic and social instability in Asia-Pacific. In Europe there is a move towards the circular economy where existing resources are reused, repaired, refurbished and recycled. With the European Commission identifying the sustainable supply of phosphorous as an important factor affecting sustainability and long-term global food security, the EU can transfer to the Asia-Pacific region circular economy best practices and technologies to increase security of supply of scarce resources, in this case the recovery of phosphorous for food production. To expedite the transfer of circular economy knowledge and innovations from Europe to Asia-Pacific the EU can use market access tools and innovation funding to not only help reduce tensions over scarce resources in the region but also support economic growth in Europe.

\section{Acknowledgement}

This research study was conducted as part of a Visiting Fellowship to the Free University of Berlin's NFG, Asian Perceptions of the EU. I would like to express my thanks to the editorial board for their helpful comments.

\section{Conflict of Interests}

The author hereby declares that there is no conflict of interests.

\section{References}

ABD (2013). Asian Development Bank Outlook 2013. Measuring water security in Asia and the Pacific. http://adb.org/sites/default/files/pub/2013/ asian-water-development-outlook-2013.pdf

EEA (2014). Resource-efficient green economy and EU policies. http://www.eea.europa.eu/publications/ resourceefficient-green-economy-and-eu

European Commission (2013). Consultative communication on the sustainable us of phosphorous. http://ec.europa.eu/environment/consultations/pdf/phosphorus/EN.pdf 
European Commission (2014). Moving towards a circular economy. http://ec.europa.eu/environment/ circular-economy/

European Commission (2014). The Partnership Instrument, advancing the EU's core interests. $h$ ttp://ec.europa.eu/dgs/fpi/what-we-do/ partnership_instrument_en.htm

European Commission (2014). Towards a circular economy: A zero waste programme for Europe. http://ec.europa.eu/environment/circular-economy/ pdf/circular-economy-communication.pdf

European Commission (2015). Climate action, environment, resource efficiency and raw materials. http://ec.europa.eu/programmes/horizon2020/ en/h2020-section/climate-action-environment-resource-efficiency-and-raw-materials

EU Gateway (2014). Opportunities for EU companies in Japan and Korea http://www.eu-gateway.eu/ home

FAO (2013). Climate change and water. http://www.fao.org/nr/water/news/clim-change. html

Herman, P. F. and Treverton, G. F. (2009). The political consequences of climate change, Survival: Global politics and strategy, 51 (2).

House of Commons (2014). Growing a circular economy: Ending a throwaway society. http://www.publications.parliament.uk/pa/ cm201415/cmselect/cmen-vaud/214/214.pdf

IRENA (2015). Renewable energy in the water, energy and food nexus. http://Www.irena.org/DocumentDownloads/Publications/IRENA_Water_Energy_Food_Nexus_2015.pdf

LSE Cities (2014). The New Climate Report. http:// newclimateeconomy.report/

PR Newswire (2014). Asia Fertilizer Industry Outlook to 2017- High Demand for Phosphate and Potash Fertilizers Driven by balanced Fertilization http://www.prnewswire.com/news-releases/ asia-fertilizer-industry-outlook-to-2017--high-de- mand-for-phosphate-and-potash-fertilizers-driven-by-balanced-fertilization-245168441.html

The Danish Government (2013). Denmark without waste: Recycle more - incinerate less. http://eng. mst.dk/media/mst/Attachments/Ressourcestrategi_UK_web.pdf

World Economic Forum (2014). Towards the circular economy: Accelerating the scale-up across global supply chains. http://www3.weforum.org/docs/ WEF_ENV_TowardsCircularEconomy_Report_2014. $p d f$ 